\title{
Peculiarities of heavy electro-mechanical plating on medium carbon steel 30 and $38 \mathrm{ChN3MA}$
}

\author{
Olga V. Gorozhankina ${ }^{1, *}$, Yury R. Kopylov ${ }^{1}$, and Alexander A. Zhirkov² \\ ${ }^{1}$ Voronezh State Technical University, 14, Moscow Avenue, Voronezh, 394026, Russia \\ ${ }^{2}$ Bryansk State Technical University, 7, 50 let Oktyabrya bul., Bryansk, 241035, Russia
}

\begin{abstract}
One of the urgent problems in mechanical engineering is development of efficient inexpensive thick-layered coatings for repair worn-out large-sized parts. To solve these problems a comparatively new method of electro-plating with simultaneous mechanical impact of a tool upon coating under formation is promising enough. In this paper there are considered the peculiarities of plating through this method of thick-layer electro-mechanical iron plating on medium carbon steel 30 and 38 ChN3MA, and the composition, structure and properties of coatings obtained are analyzed. Coatings were applied upon crank main journals made of steel 38ChN3MA and upon models imitating crank main journals made of steel 30. Micro-hardness of the coating obtained, roughness, a chemical composition and a structure were analyzed. The results of the investigations have shown that a more significant role in hardness increase is played not by a chemical composition of medium carbon steel upon which it is applied, but a preparation of the surface and the technology of coating and also an electrolyte composition. The structure of electro-mechanical plating is less defective, contains a value of detrimental impurities considerably lower of allowable values and has a satisfactory adhesion strength with a substrate.
\end{abstract}

\section{Problem definition}

At present one of the urgent problems in mechanical engineering is development of efficient and inexpensive heavy coatings for repair of worn large-sized parts [9, $10,11]$. Such coatings must have an increased thickness, good durability of adhesion with a basis, sufficient hardness and wear-resistance. In world practice the reduction of worn-out large-sized parts is carried out by retailoring [12, 13, 14], sputtering [15, 16, 17], cladding $[18,19,20]$ and so on. But all these methods suppose an intensive thermal impact upon a part under reduction that results in hard-removable buckling and shrinkage.

Therefore, more and more attention is paid to the process of galvano-mechanical metal deposition without temperature increase - flow-contact deposition of galvanoplatings with the mechanical activation of a cathode surface $[5,6,7,8]$. It is well-known that the mechanical effect upon a part in the course of galvanic deposition allows increasing the allowable current density, a deposition rate, micro-hardness, coating thickness and also improving the adhesion with a basis and decreasing residual stresses.

\section{Investigation procedure and equipment}

The considered in this paper off-bath method of the restoration through an electro-galvanic dry topping in a flowing electrolyte with the mechanical effect by a smoothing tool in the course of deposition is realized at small temperatures $\left(40-50{ }^{\circ} \mathrm{C}\right)$. It prevents buckling and shrinkage in parts and ensures the required thickness (1.5 - $1.8 \mathrm{~mm}$ ), micro-hardness (600 - 650 HV) and low roughness $(\operatorname{Ra} 1.25-2.5 \mu \mathrm{m})$ stipulating for a small allowance for the further grinding of a layer restored. The method has small material and power expenses and a quick recoupment at the espense of the application of ecologically acceptable inexpensive electrolyte of iron chloride. The restored layer contains detrimental impurities considerably lesser of admissible values and has satisfactory strength of adhesion with the basis (200 $-250 \mathrm{MPa}$ ).

Taking into account that at the current moment the works on electro-galvanic mechanical coatings are precious few and the investigation of their composition and structure were practically not carried out and it seems to be expedient to consider this problem in relation to some medium carbon kinds of steel used for manufacturing large-sized parts which further are supposed to be reduced according to the given technology.

For the possibility of practical use of such coatings during the repair of worn large-sized parts (shafts) there was carried out an investigation on the application and properties of a electro-galvanic mechanical coating (EGMC) upon worn parts of a diesel engine crankshaft.

A crankshaft of diesel engine 1A-5D49 is produced of steel 38ChN3MA in Russia. Dimensions: length is $3951 \mathrm{~mm}$; the diameter of main necks is ø $219 \mathrm{~mm}$.

* Corresponding author: winter.07@mail.ru 
Journals are nitrided, the depth of a nitrided layer is $0.5 \ldots 0.7 \mathrm{~mm}$. The requirements to journals reduced are the following: hardness of a reduced layer is to be not less than HV 460, at the thickness not less than $400 \mu \mathrm{m}$; the adhesion strength of the reduced layer with the basis not less than $100 \ldots 150 \mathrm{MPa}$; roughness Ra is $0.16 \mu \mathrm{m}$. Coatings are to be carried out on crank main journals cut out preliminarily from a basic part (Fig. 1). At that the journals friction wear at which the further operation is already impossible makes about $0.5 \ldots 0.7 \mathrm{~mm}$, that is, is equal to the depth of a nitrided layer. The residual margin of fatigue resistance is $55 \ldots 70 \%$. For plating there is used a specially developed device (Fig. 2).

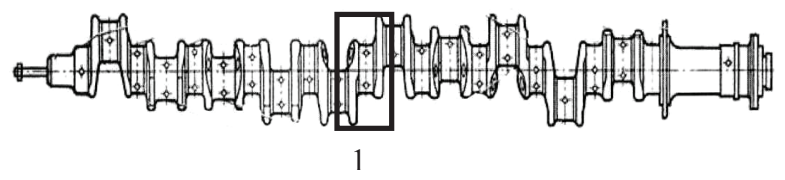

Fig. 1. Crankshaft of a diesel engine; 1 - crank main journal
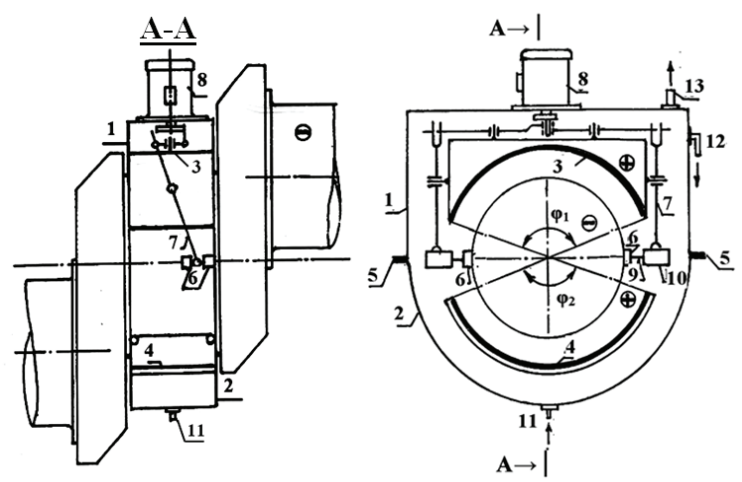

Fig. 2. Device for electro-galvanic mechanical plating: 1,2 two halves of a split container; 3,4 - anode two parts; 5 - seal; 6 - tool for smoothing; 7,9-levers; 8,10 - electrical drive; 11 outlet for electrolyte feed; 12 - outlet for electrolyte discharge; 13 - outlet for removal of hydrogen formed.

The device contains an electro-galvanic cell as a split conatiner, anode consisting of two parts and a tool for smoothing a coating layer under formation. As anode there are used electrodes made of steel 30. As tools for the mechanical effect upon a layer under reduction the mineral ceramic plates are used. Flow electrolyte is fed into a cell. A part rotates, at current supply begins a process of iron sedimentation on a part surface and at the same time a surface of the part is smoothed by a mineral ceramic tool. At the same time the effort for tool pressure to the coating surface is normalized, a tool performs reciprocating movements.

A very significant moment is a preparation of a part surface to sedimentation, in particular, an electrochemical pickling. As a rule, a pickling is carried out in a separate bath and during the transfer of the prepared part from the bath of pickling into the bath of sedimentation on the surface of the part there is appeared a thin juvenile layer of oxides which decreases considerably adhesion strength of a coating with main metal.

In our case pickling is carried out in the bath of dry topping without oxygen access in order to decrease or even exclude completely the formation of an oxide layer and increase the adhesive strength of a coating with main metal. After the surface preparation the electrolyte of pickling is pumped out from a cell, a bath is washed out and further an electrolyte of dry toppong is supplied in a cell in a flow mode (consumption $10 \mathrm{l} / \mathrm{min}$ ) which is performed already up to the end of the process of electro-galvanic mechanical dry topping.

Sedimentation begins with the realization of the socalled accelerating mode:

- $\mathrm{dc}$ is supplied to the part under reduction in the course of $5 \mathrm{~min}$ at the least values of cathode current density $\mathrm{i}_{\mathrm{K}}=500 \mathrm{~A} / \mathrm{m}^{2}$;

- current density increases gradually up to operational values $2500 \mathrm{~A} / \mathrm{m}^{2}$ in the course of $10-15 \mathrm{~min}$;

- after this for the obtaing of an electro-galvanic mechanical coating there is included a mechanical impact in the process which effects a surface of sedimentation by a polished electro-chemically neutral tool adjusted beforehand to the essential parameters. In the course of sedimentation a temperature, a concentration and acidity of electrolyte, current density are supported constantly.

The average value of the initial micro-hardness (before coating) of a shaft main journal was obtained according to 48 measurements and makes HV 325 units; an error from HV 18 up to HV 26. The average value of micro-hardness of the obtained EGM coating after polishing is obtained according to 120 measurements and makes HV 730 units; an error from HV 20 up to HV 54.

The thiskness of EGM coating for one side is 0.85 $\mathrm{mm}$; the diameter of of a shaft journal with coating after polishing is $\varnothing 220.4 \mathrm{~mm}$. The coating according to geometry and hardness corresponds to the technical specification.

Coating roughness $\mathrm{Ra}$ according to data of 10 measurements is $0.325-0.45 \mu \mathrm{m}$ and does not exceed the requirements of the drawing Ra $0.63 \mu \mathrm{m}$.

These results are obtained at Voronezh Engineering Plant in the central measurement laboratory.

For convenient investigations with the aid of a metallographic microscope and for a more thorough study of the structure, EGM- and electrogalvanic (EG) coating is applied on the surface of cylindrical hollow samples made of steel 30 . The dimensions of models imitating journals of crankshafts are the following: length $100 \mathrm{~mm}$, external diameter $\varnothing 60 \pm 0.2 \mathrm{~mm}$, inner diameter $\varnothing 54 \pm 0.2 \mathrm{~mm}$ (Fig. 3, a). The average hardness of a test surface of samples before dry topping HV 230-250.

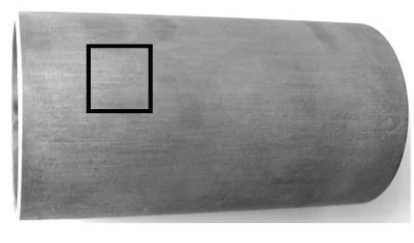

a

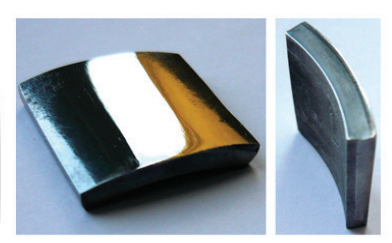

b
Fig. 3. Overview of the model of the part with an outer surface prepared for dry topping - a; metallographic sample for metallographic investigations cut out from a cylindrical model of the part - b 
Electrolyte composition and sedimentation modes of EGM- and EG coatings are shown in Table 1.

Table 1. Electrolyte composition and sedimentation modes of EGM- and EG coatings

\begin{tabular}{|l|c|c|}
\hline \multicolumn{1}{|c|}{$\begin{array}{c}\text { Sedimentation } \\
\text { parameters }\end{array}$} & $\begin{array}{c}\text { With } \\
\text { mechanical } \\
\text { effect }(\mathrm{EGM})\end{array}$ & $\begin{array}{c}\text { Without } \\
\text { mechanical } \\
\text { effect } \\
\text { (EG) }\end{array}$ \\
\hline $\begin{array}{l}\text { Electrolyte iron } \\
\text { composition in }\end{array}$ & $\mathrm{FeCl}_{2} \cdot 4 \mathrm{H}_{2} \mathrm{O}$ & $\mathrm{FeCl}_{2} \cdot 4 \mathrm{H}_{2} \mathrm{O}$ \\
\hline $\begin{array}{l}\text { Chloride } \\
\text { concentration } \\
\text { electrolyte, } \\
\mathrm{kg} / \mathrm{m}^{3}\end{array}$ & 350 & 350 \\
\hline $\begin{array}{l}\text { Electrolyte } \\
\text { temperature, } \mathrm{T},{ }^{0} \mathrm{~K}\end{array}$ & 333 & 333 \\
\hline $\begin{array}{l}\text { Electrolyte acidity, } \\
\text { pH }\end{array}$ & 1,0 & 1,0 \\
\hline $\begin{array}{l}\text { Cathode current } \\
\text { density, } \mathrm{i}_{\mathrm{K}}, \mathrm{A} / \mathrm{m}^{2}\end{array}$ & 2500 & 2500 \\
\hline $\begin{array}{l}\text { Tool pressing force to } \\
\text { coating surface, } \mathrm{F}, \mathrm{H}\end{array}$ & 2 & - \\
\hline $\begin{array}{l}\text { Frequency of tool } \\
\text { reciprocating } \\
\text { displacements, } \omega_{\mathrm{n}}, \\
\text { min-1 }\end{array}$ & 40 & - \\
\hline $\begin{array}{l}\text { Circumferential part } \\
\text { velocity of } \\
\text { rotation, } \mathrm{V}_{0}, \mathrm{~m} / \mathrm{sec}\end{array}$ & 0,2 & 6,2 \\
\hline $\begin{array}{l}\text { Electrolysis time } \\
\text { support, } \mathrm{t}, \mathrm{h}\end{array}$ & 6 & \\
\hline
\end{tabular}

\section{Research results and their analysis}

After having obtained a coating one cuts from the part some samples with dimensions about $22 \times 22 \times 3 \mathrm{~mm}$ and further they are under analysis (Fig. 3, b). In case of EG coating the surface for the sedimentation is prepared in a common way in a separate bath for pickling. A chemical composition of EGM coating and a basic metal are analyzed through Coulomb metering method with the aid of express-analyzers. At that the percentage of the content of carbon, hydrogen and sulfur in a surface layer (Table 2).

Table 2. Chemical composition of EGM coating and basic metal

\begin{tabular}{|c|c|c|}
\hline \multicolumn{2}{|c|}{ Chemical composition of EGM coating and basic metal } \\
\hline \multirow{2}{*}{$\begin{array}{c}\text { Chemical } \\
\text { element }\end{array}$} & \multicolumn{2}{|c|}{ Content, \% } \\
\cline { 2 - 3 } & $\begin{array}{c}\text { Basic metal, steel } \\
30\end{array}$ & EGM coating \\
\hline Carbon $(\mathrm{C})$ & 0.223 & 0.086 \\
\hline Hydrogen $(\mathrm{H})$ & 0.0042 & 0.0043 \\
\hline Sulfur $(\mathrm{S})$ & 0.0088 & 0.0021 \\
\hline
\end{tabular}

According to the results of the investigation hydrogen content in EGM coating is small (0.004 $0.005 \%$ ) which corresponds approximately to hydrogen quantity $(0.0042 \%)$ in basic material (steel 30 ) obtained in a metallurgical way. It may be explained by that the adatoms of hydrogen from the surface of the coating deposited are eliminated systematically and quickly enough by a smoothing tool that is why it is possible to suppose that such a low content of hydrogen in the coating obtained depends just upon this. As a rule in electro-plated coatings without a mechanical effect the hydrogen content is higher and makes $0.0098-0.01 \%$, that increases brittleness.

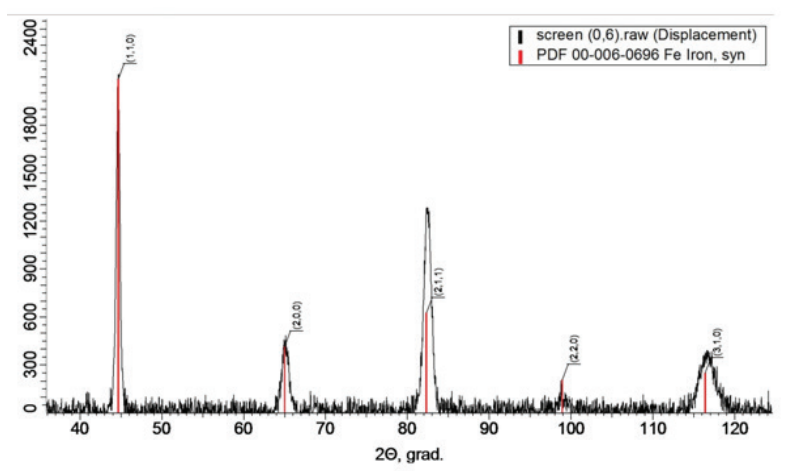

Fig. 4. Diffractogram of a heavy (1.8 $\mathrm{mm}$ for one side) EGM iron coating obtained on the diffrectometer of D2Phaser Bruker type with the use of $\mathrm{Cu}$-radiation

The fulfilled analysis of X-ray diffractograms of EGM coating (Fig. 4) has revealed the existence of a solid solution on the basis of lettice $\alpha$-Fe to which points out a certain displacement of diffraction maximums regarding their position on the diffractograms of pure iron plating. Such a displacement points out to the presence a small quantity of admixtures in an iron coating which is confirmed by the results of Coulomb metering and electronic analysis. The obtained diffractogram of EGM heavy iron coating is a common diffractogram of a polycrystal and represents a set of peaks on a smooth line of the background. According to data of the X-ray structural analysis the substance under investigation is single-phase.

In general case of electroplated coatings obtained in chloride, sulfated and other iron electrolytes there is observed an obvious lamination of the structure caused by layers formed occasionally on a cathode with a large content of hydroxides. On their surface there are formed layers of polycrystals with a metal structure and a considerably lesser content of hydroxides [1] (Fig. 5, b).

During the investigation of EGM heavy iron coatings on the optical microscope a lamination is not detected (Fig. 5, a). It is explained, in the author's openion, with that a smoothing tool affects occasionally and intensive upon coating crystals formed and contributes to electrolyte mixing at the cathode and also to the partial purification of a cathode layer from hydroxides which eliminates an interval in the formation of layers with hydroxide insertions. The application of the mechanical effect with a smoothing tool results in the formation of a more dense and even structure of EGM coating.

One of the significan parameters of EG and EGM coating is thiskness. A maximum obtained thickness of a coating and the dependence of its increase upon the time of a process for EGM dry topping and common EG dry topping without a mechanical effect are under investigation. The results of the investigation are shown in the graph (Fig. 6). 


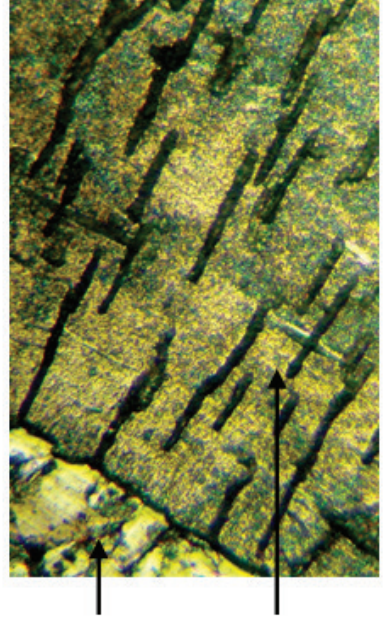

Basis coating a, $x 1000$ b, $x 1000$

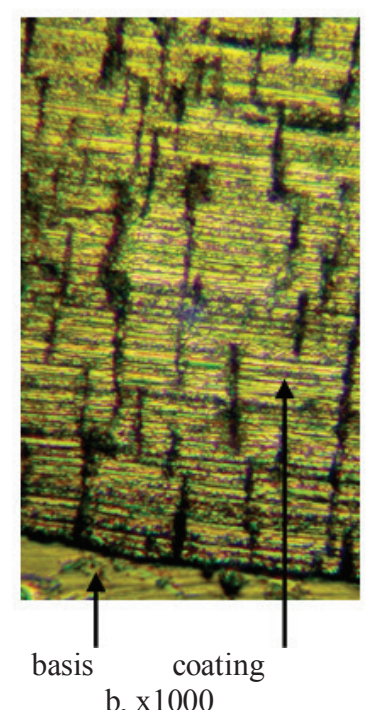

Fig. 5. Coating microstructure on a microsection: a - EGM coating; $b$ - EG coating obtained at the same mode

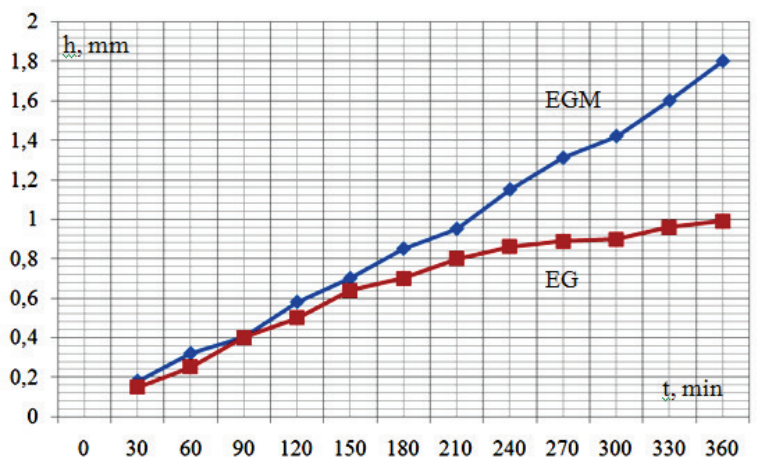

Fig. 6. Dependence of the thickness of EGM and EG coating upon the sedimentation time

The maximum achieved thickness of EGM coating during the 6 hours period of sedimentation makes 1.8 $\mathrm{mm}$ without a layer increase delay. In EG coating occurs an increase delay of the sedimentation thickness; a general thickness of a layer during the 6 hours period of sedimentation makes less than $1.4 \mathrm{~mm}$. In such a way as compared with a common bath electro-galvanic dry topping an electro-galvanic mechanical dry topping allows obtaining a layer of the thickness large enough without time delay in the process efficiency.

The investigations of micro-hardness are carried out on a micro-hardness meter PMT-3. The micro-hardness of the main metal (steel 30) was $230-250 \mathrm{HV}$. The micro-hardness of EGM coating was 600 - 717 HV.

On the basis of data obtained there was formed a histogram (Fig. 7) showing the dependence of the microhardness of a layer obtained upon the steel grade of initial material.

The micro-hardness of EGM coating obtained through the plating on steel 38ChN3MA does not exceed substantially the micro-hardness of EGM coating obtained through the plating on steel 30 . It could be drawn a conclusion that a more significant role is played in hardness increase in coatings obtained not by a chemical composition of medium carbon steel upon which a coating is applied, but a surface preparation and a plating technology and also an electrolyte composition. The adhesion strength (according to Ollard-Melkov method) of the coating with the basis, $\sigma_{a d}$ at the surface preparation only by a standard pickling reaches values 38.5 - 57.7 MPa (for EG coating).

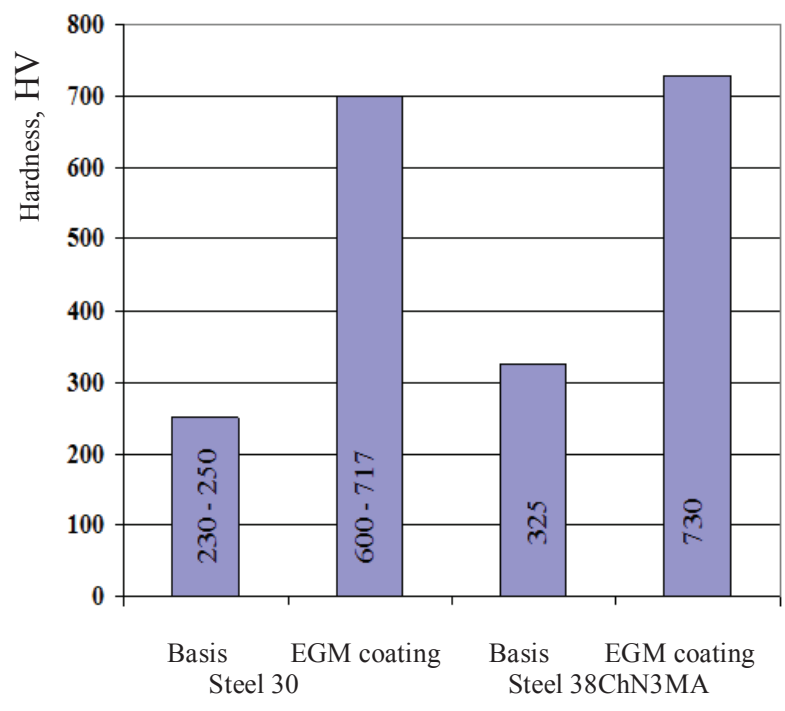

Fig. 7. Dependence of hardness of EGM coating upon a steel grade of initial material

Pickling in a dry topping bath prepared for surface sedimentation allows increasing values of the adhesion strength, $\sigma_{\text {ad }}$ up to 201.2 - $247.4 \mathrm{MPa}$ (for EGM coating), that is, approximately five times with regard to a common pickling in a sulfate bath. As a part is not transferred into another bath and it does not have contact with air, then on its surface there are no foreign matters and no oxide films are formed that ensures the best adhesion strength of a coating with the basis.

\section{Conclusions}

In accordance with data of Yu.N. Petrov, G.N. Zaidman et al. $[2,3]$ it was established that the peculiarity of the structure electrolytic iron is the utmost workhardening of this material and the 'frost' of its defects. Just this peculiarity forms the highest iron strength and determines its capacity to resist successfully friction and wear and also other motion deformations.

In our case the whole amount of EGM coating is workhardened - strengthened in a layer-by-layer way by the impact of a smoothing tool and as a result of this there is formed a large density of dislocations. In such a way, a layer of electro-galvanic mechanical iron possesses a sufficient micro-hardness and wear-resistance which is confirmed by data shown in [4].

\section{References}

1. E.D. Pleshka, Electric Methods of Surface Treatment 44 (4), 17 (2008) 
2. Yu.N. Petrov, G.V. Guriyanov, Zh.I. Bobanova, S.P. Sidelnikova, L.N. Andreeva, Electrolytic Deposition of Iron (Kishinyov, Shtiintsa, 1990)

3. I.M. Kovensky, V.V. Povetkin, Metal science of coatings (Moscow, SP Intermet Engineering, 1999)

4. Yu.R. Kopylov, A.V. Tolcheev, Problems of Machines Quality and Their Competitive Ability (Bryansk: BSTU, 2008).

5. M. Schlesinger, M. Paunovic, Modern electroplating (John Wiley \& Sons, 2011)

6. P.C. Andricacos, IBM Journal of Research and Development, 42(5), 567 (1998)

7. M.R. Vaezi, S.K.Sadrnezhaad, L. Nikzad, Colloids and Surfaces A: Physicochemical and Engineering Aspects, 315(1), 176 (2008)

8. Q.X. Liu, S.Z. El Abedin, F. Endres, Surface and Coatings Technology, 201(3), 1352 (2006)

9. M. Berger, Surface Engineering, 18(3), 219 (2002)

10. Y. Zhang, Materials Letters, 69, 86 (2012)

11. M. Berger, Surface Engineering, 18(3), 219 (2002)

12. R.L. Deuis, J.M. Yellup, C. Subramanian, Composites science and technology, 58(2), 299 (1998)

13. N. Murugan, R.S. Parmar, Journal of Materials Processing Technology, 41(4), 381 (1994)

14. H.J. Kim, B.H. Yoon, C.H. Lee, Wear, 249(10), 846 (2001)

15. H. Assadi, Acta Materialia, 51(15), 4379 (2003)

16. P. Fauchais, Journal of Physics D: Applied Physics, 37(9), R86 (2004)

17. Y. Yang, K.H. Kim, J.L. Ong, Biomaterials, 26(3), 327 (2005)

18. L. Shepeleva, Surface and Coatings Technology, 125(1), 45 (2000)

19. L. Sexton, Journal of Materials Processing Technology, 122(1), 63 (2002)

20. Y.P. Kathuria, Surface and Coatings Technology, 132(2), 262 (2000) 